\title{
Prediction of the Mechanical Properties of P91 Steel by Means of Magneto-acoustic Emission and Acoustic Birefringence
}

\author{
Katarzyna Makowska $^{1} \cdot$ Leszek Piotrowski $^{2} \cdot$ Zbigniew Ludwik Kowalewski $^{3}$
}

Received: 15 July 2016 / Accepted: 14 May 2017 / Published online: 29 May 2017

(C) The Author(s) 2017. This article is an open access publication

\begin{abstract}
The paper describes an application of nondestructive volumetric magnetic and ultrasonic techniques for evaluation of the selected mechanical parameter variations of P91 steel having direct influence on its suitability for further use in critical components used in power plants. Two different types of deformation processes were carried out. First, a series of the P91 steel specimens was subjected to creep and second, one to plastic deformation in order to achieve the material with an increasing strain level up to $10 \%$. Subsequently, non-destructive and destructive tests were performed. Magnetic methods based on measurements of magnetoacoustic emission and magnetic hysteresis loop changes as well as the ultrasonic method based on acoustic birefringence measurements, were applied. Finally, the static tensile tests were carried out in order to evaluate the mechanical parameters. It is shown that some relationships between the selected parameters coming from the non-destructive and destructive tests may be formulated.
\end{abstract}

Keywords Creep - Plastic deformation - Acoustic birefringence $\cdot$ Magnetoacoustic emission $\cdot$ Magnetic hysteresis loop

Katarzyna Makowska

katarzyna.makowska@its.waw.pl

1 Motor Transport Institute, 80 Jagiellońska St., 03-301 Warsaw, Poland

2 Gdańsk University of Technology, 11/12 Narutowicza St., 80-233 Gdańsk, Poland

3 Institute of Fundamental Technological Research, Polish Academy of Sciences, 5B Pawińskiego St., 02-106 Warsaw, Poland

\section{Introduction}

Various non-destructive methods have been used to evaluate material degradation due to creep [1-7]. Among them one can indicate a magnetoacoustic emission technique [2,3] or Barkhausen noise method [4,5] for example. A review of various non-destructive techniques that allow the evaluation of creep damage progress was presented by Sposito et al. [6].

The magnetoacoustic emission (MAE) technique is based on the analysis of acoustic signals generated in the bulk of the material subjected to alternating magnetic fields [7]. MAE is generated during the movement of non- $180^{\circ}$ domain walls (in the case of steels they are $90^{\circ}$ domain walls) as a result of local deformations (volume changes) induced by the local change of magnetisation in a material having the non-zero magnetostriction [8]. Domain walls are pinned temporarily by microstructural barriers to disable their motion, and then they are released abruptly with an increase of the magnetic field. Grain boundaries, precipitates, dislocation tangles [9] and voids [10] are microstructural barriers hindering domain walls movement. It was also suggested that irreversible rotation of the domain through angles other than $180^{\circ}$ can also contribute to the MAE signal [11]. Magnetoacoustic emission accompanies magnetic Barkhausen effect (MBE) [8] that is produced in steels by movement of both $180^{\circ}$ and $90^{\circ}$ domain walls. Movement of the $180^{\circ}$ domain walls (between anti-parallel domains) do not contribute to the generation of elastic waves. Stresses are not generated as the result of $180^{\circ}$ domain walls movements or rotations, since the strain along a particular axis is independent on the direction of the magnetic moments if they act along the same axis [8]. As a consequence, the movement of $180^{\circ}$ domain walls do not affect magnetostrictive strain [8]. An advantage of the MAE method over the MBE method results from the depth of measurements. In the case of MAE it is dependent only 
on the ability to magnetise the investigated material and easily reaches $10 \mathrm{~mm}$ (or even more in special cases) while for MBE it is only $0-1 \mathrm{~mm}$ due to attenuation of the generated electromagnetic waves (in the $\mathrm{kHz}$ range) by eddy currents [10].

Taking into account a good sensitivity to the precipitation process development [7,12] as well as stress variation [8], the magnetoacoustic emission was chosen in this research.

It has been found that various ultrasonic techniques can be applied to evaluate the quality of the material in the asreceived state and after deformation history induced by creep or plastic flow. Mutual relationships between parameters of ultrasonic waves and creep damage were observed [13,14]. Variations of nonlinear acoustic parameters were investigated in the course of creep [15]. In late creep stages, when numerous voids have been created in the bulk steel specimens, an ultrasonic technique based on acoustic birefringence was used to detect material damage [16].

Measurement of acoustic birefringence and evaluation of magnetic parameters seem to be able to provide more comprehensive material degradation data than the replica technique and destructive tests. Acoustic birefringence can be measured using ultrasonic echo technique, for elements accessible from one side only (like pipes for example). Its value is proportional to the difference in the round-trip travel time of ultrasonic pulses polarized in the direction parallel and perpendicular to the loading direction and, at the same time, perpendicular to the loading direction of the specimen. It can be calculated as [17]:

$B=2 \cdot \frac{V_{p}-V_{l}}{V_{l}+V_{p}}=2 \cdot \frac{t_{l}-t_{p}}{t_{l}+t_{p}}$

where $V_{p}$ velocity of shear wave polarized along loading axis, $V_{1}$ velocity of shear wave polarized perpendicular to loading axis, $\mathrm{t}_{1}$ time of flight of the shear wave polarized along loading axis, $t_{p}$ time of flight of the shear wave polarized perpendicular to loading axis.

The value of acoustic birefringence depends on various factors influencing the velocity of ultrasonic waves. One can indicate a material texture (preferred grain orientations), concentration and orientation of voids (if any), impurities and dislocation in the bulk of the material, and applied residual stresses in the material.

The advantage of acoustic birefringence measurements is the fact that there is no need to know the exact thickness of the element under test. They do not depend on temperature and they deliver information averaged over the element thickness. Because of these features, this technique has found a wide application in ultrasonic residual stress evaluation in the rims of mono-block railway wheels [18].

Non-destructive and destructive tests performed on specimens made of two grades of steel used in power plants, subjected to creep and tensile deformation, were described earlier [19]. It was shown that values of this acoustic parameter were different for specimens subjected to creep and subjected to tensile test at low temperatures.

The aim of the paper is to estimate the mechanical properties of steel in the course of creep and tensile deformation using parameters determined by means of magnetoacoustic emission method, parameters coming from magnetic hysteresis loops measurements and ultrasonic acoustic birefringence coefficient as well.

Specimens made of P91 steel were subjected to an accelerated creep tests. It is unrealistic to expect that in material subjected to such loads (relatively short period of time, high temperature and stress) the same phenomena will occur as in material subjected to much lower stress and temperature but for a very long period of time. However, the accelerated creep test is the only way to "produce" damaged specimens in a reasonable time, and to test various nondestructive techniques that may detect changes in various material parameters. In this work, the problem is approached differently: the influence of various damage mechanisms on the parameters arising from non-destructive measurements is investigated.

\section{Material}

The low carbon, creep-resistant P91 steel, typically used for tubes, plates and structural components in the power plant industry, was tested. Its chemical composition is shown in Table 1.

The tested material consists of tempered martensite phase. According to Panait et al. [20] and computed phase diagrams presented by Šohaj et al. [21], the P91 steel is stabilized by $\mathrm{M}_{23} \mathrm{C}_{6}$ carbides (where $\mathrm{M}=\mathrm{Cr}, \mathrm{Fe}, \mathrm{Mo}$ ) and $\mathrm{MX}$ carbonitrides (where $\mathrm{M}=\mathrm{V}, \mathrm{Nb}$ and $\mathrm{X}=\mathrm{C}, \mathrm{N}$ ). The specimens of the tested material were cut from a section of a thick-walled pipe (thickness of $60 \mathrm{~mm}$ and diameter of about $270 \mathrm{~mm}$ ) along its axis.

Table 1 Chemical composition of P91 steel

\begin{tabular}{llllllllllllll}
\hline $\mathrm{C}$ & $\mathrm{Si}$ & $\mathrm{Mn}$ & $\mathrm{P}$ & $\mathrm{S}$ & $\mathrm{Cr}$ & $\mathrm{Mo}$ & $\mathrm{Ni}$ & $\mathrm{Al}$ & $\mathrm{Cu}$ & $\mathrm{Ti}$ & $\mathrm{Nb}$ & $\mathrm{V}$ & $\mathrm{Fe}$ \\
\hline 0.085 & 0.27 & 0.30 & 0.015 & $<0.01$ & 8.2 & 0.86 & 0.16 & 0.010 & 0.14 & $<0.01$ & 0.098 & 0.19 & $\mathrm{Balanced}$ \\
\hline
\end{tabular}

Numbers denote percentage by weight 


\section{Experimental Methods}

Magnetoacoustic emission intensity, coercivity, saturation induction and acoustic birefringence coefficient were measured on the plain specimens of the P91 steel (having a cross section $5 \mathrm{~mm} \times 7 \mathrm{~mm}$ and gauge length of $40 \mathrm{~mm}$ ). The specimens were earlier subjected either to creep $(T=773$ $\mathrm{K}, \sigma=290 \mathrm{MPa})$ or plastic deformation $(\mathrm{T}=298 \mathrm{~K}, \mathrm{~V}$ $=1 \mathrm{~mm} / \mathrm{min}$ ). The loading process of each specimen was carried out to achieve the different strain level. The creep process was interrupted to obtain various deformation levels i.e.: $0.85,1.85,3.15,4.60,5.90,7.90$ and $9.30 \%$, whereas the levels of plastic deformation were as follow: 2.00, 3.00, 4.50, $5.50,7.50,9.00,10.50 \%$. The programmes of the interrupted tensile tests are presented in Fig. 1a, b, respectively.

The set-up for measuring the magnetoacoustic emission and the magnetic hysteresis loop variation is shown in Fig. 2. The specimen (1) is magnetized with the driving coil (2) applying a triangular waveform of current with frequency of about $0.1 \mathrm{~Hz}$ [2]. The core (4) was used to close the magnetic flux. The pick-up coil (3) provides a voltage signal which is
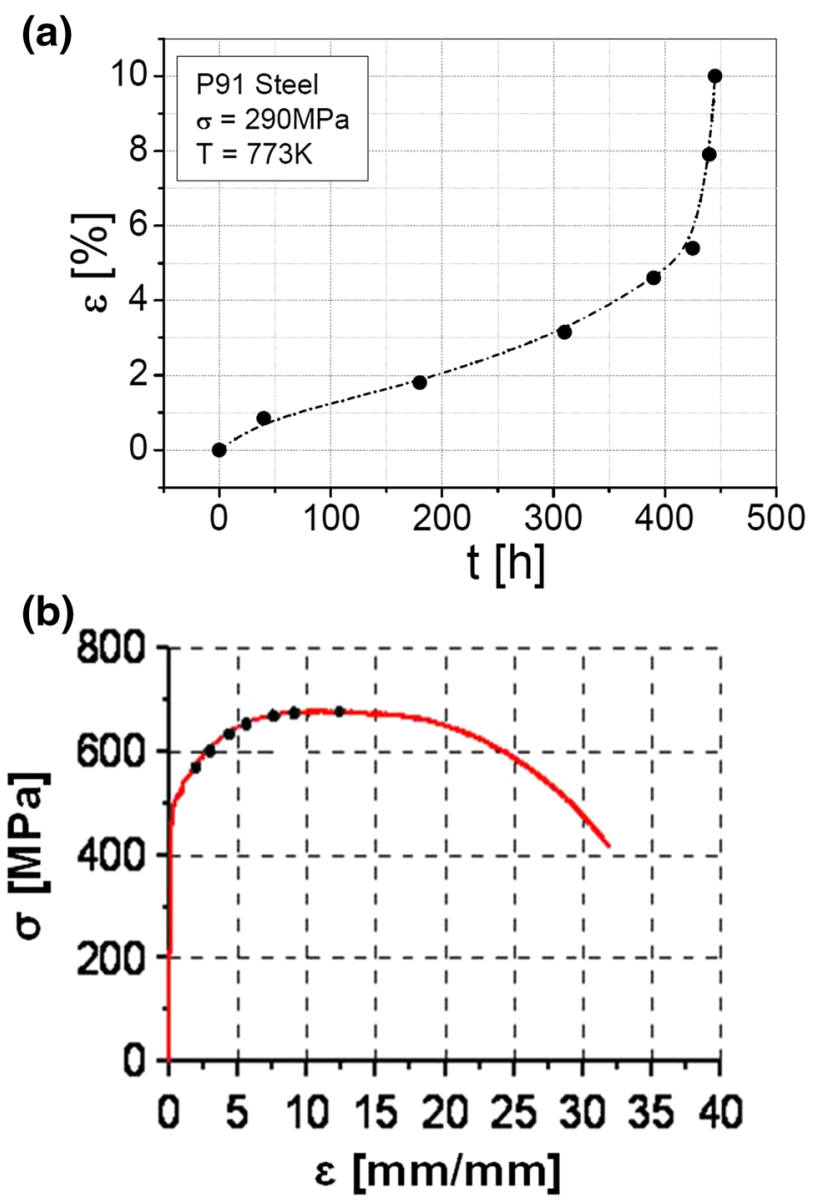

Fig. 1 a Programme of interrupted creep process of the P91 steel. b Programme of interrupted plastic deformation of the P91 steel

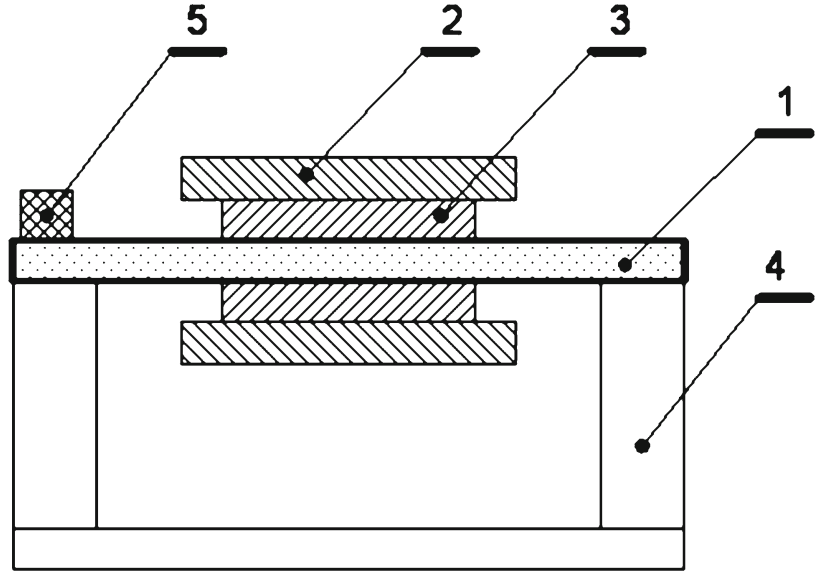

Fig. 2 The measuring set for magnetoacoustic emission and magnetic hysteresis loop investigations ( 1 specimen, 2 driving coil, 3 pick-up coil, 4 core, 5 piezoelectric transducer)

used to obtain the magnetic hysteresis loop $\mathrm{B}(\mathrm{H})$ [2]. The magnetoacoustic emission signal was measured by means of the piezoelectric transducer (5).

Envelopes of the magnetoacoustic emission signal were calculated according to the equation:

$U_{a}(h)=\sqrt{\frac{\int_{0}^{\tau} U_{t a 1}^{2}(t) d t}{\tau}}$

where $U_{a}(h)$ is the root mean square voltage from the acoustic wave sensor calculated over an interval $\tau$ during which the average magnetic field was h. $U_{\mathrm{tal}}(t)$ is the output of the sensor.

The integral over a half cycle of the magnetic field was calculated as

$\operatorname{int}\left(U_{a}\right)=\int_{H \min }^{H \max } U_{s a}(h) d h$

where

$U_{s a}(h)=\sqrt{U_{a}^{2}(h)-U_{t a}^{2}}$

and $\mathrm{U}_{\mathrm{ta}}$ is the root mean square of the background noise voltage.

Hysteresis loop changes were characterised by means of coercivity $\mathrm{H}_{\mathrm{c}}$ and saturation induction $\mathrm{B}_{\mathrm{s}}$.

The magnetic parameters were normalized with respect to their values for the non-deformed specimen $\left(\operatorname{Int}\left(\mathrm{U}_{\mathrm{a}}\right)_{\text {norm}}\right.$, $\left.\mathrm{H}_{\mathrm{c} \text { norm }}, \mathrm{B}_{\mathrm{s} \text { norm }}\right)$.

Ultrasonic measurements were performed in five spots on each specimen along gauge length. In this way, in specimens 
Fig. 3 Spots of ultrasonic measurements

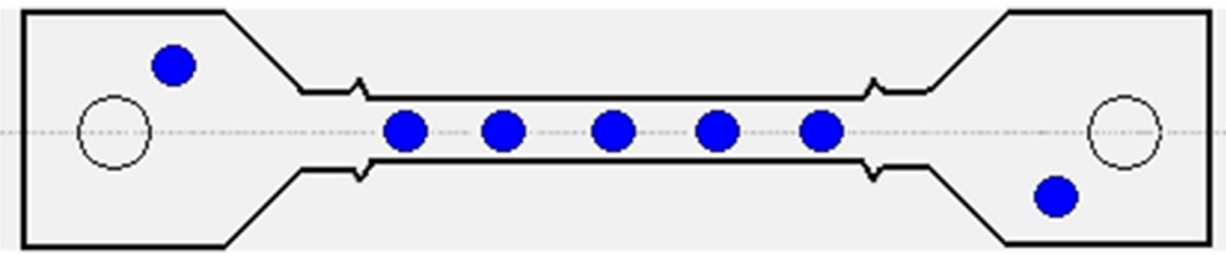

exhibiting necking, the maximal value of acoustic birefringence coefficient could be found. Measurements were taken with a $5 \mathrm{MHz}$ shear wave piezoelectric transducer coupled to the specimen surface by means of a viscous epoxy couplant. Spots for measurements performed with ultrasonic techniques on the specimen are presented in Fig. 3.

Subsequently, the specimens were subjected to static tensile tests in order to determine the yield stress and ultimate tensile stress. The relationships between the strain level and the parameters obtained from the ultrasonic/magnetic tests, as well as the relationships between the mechanical and ultrasonic/magnetic parameters, were evaluated.

\section{Results and Discussion}

Example envelopes of magnetoacoustic emission are presented in Fig. 4. The MAE envelope of the non-deformed specimen reveals a broad maximum with two peaks (Fig. 4a). According to [22] the first peak on the MAE envelope is mainly due to the creation and the second one to the annihilation of magnetic domains with high contribution of displacement of non- $180^{\circ}$ domain walls. The changes in the height and width of the peaks in Fig $4 \mathrm{~b}, \mathrm{c}$ indicate that magnetoacoustic emission is sensitive to material damage and depends on the type of deformation. The two-peak broad maximum observed in the non-deformed specimen transforms to a single maximum for the specimen strained up to $10.5 \%$ in the tensile test (Fig. 4b) as well as for the specimen strained up to $9.3 \%$ in the creep test (Fig. 4c). It can be also noted that the single maximum for the specimen after plastic deformation is broader and lower than for the specimen after creep (Fig. 4b, c), which will be discussed later. It can also be seen that the maxima of both envelopes of strained specimens (by creep and plastic deformation) occur at a higher magnetizing field than the maximum of the non-deformed specimen. One explanation is that it is necessary to use a higher magnetic field to be able to move domain walls in the material with a higher density of dislocations introduced.

Transformation of the peak shape for all deformed specimen occurs. The integrals of half-period voltage signals from the magnetoacoustic emission rms envelopes for each specimen were calculated. They are presented in Fig. 5.

The integral of the half-period voltage signal of the MAE $\operatorname{Int}\left(U_{a}\right)_{\text {norm }}$ decreases with the increase of strain level for both plastic and creep deformations, but the dynamics of these processes are different-lower values of this parameter (for deformation values greater than $\varepsilon=2 \%$ ) were obtained for specimens after plastic deformation (Fig. 5). The integral of the MAE is almost insensitive to creep deformation in the range of strain between 0.85 and $9.3 \%$. The decrease of both parameters may be explained on the basis of previous knowledge provided by other researchers $[2,23,24]$. The plastic deformation produces defects inside the martensite plates in the form of dislocation tangles that decrease significantly the mobility of 'non- $180^{\circ}$ ' domain walls [2]. An increase in dislocations density reduces the mean free path of the domain walls displacement and increases their pinning force [23]. According to the Granato-Lucke theory, it is believed that the ends of the dislocations lines are fastened at points of strong and weak fixation. The points of strong fixation are the nodes of the dislocation network, whereas the points of weak fixation are impurity atoms [24]. Under applied stresses the dislocations segments bend between the points of weak fixation. In the case, when the stress exceeds a defined value, the dislocation segment breaks away from the points of weak fixation [24]. As a result, due to the dislocation structure modification, movement of the domain walls becomes less effective and the MAE intensity signal and its parameters $\operatorname{Int}\left(\mathrm{U}_{\mathrm{a}}\right)$ decrease monotonically [10].

Usually, in the case of creep of metallic materials, two main processes are dominant: strain hardening and thermal softening (also called as recovery) $[25,26]$. The same situation takes place in the P91 steel. The material recovery occurs by dislocation cross slip and dislocation climb. As a result of recovery and relatively high level of acting stress equal to $290 \mathrm{MPa}$, polygonization of the material occurs thanks to the dislocation climb mechanism. The second important process involved during creep of the P91 steel is the hardening caused by introduction of high density dislocation tangles to the material structure. Therefore, the accelerated creep that is achieved is a mixed process consisting of creep and plastic components of deformation due to high level of stress applied. Similarly, for plastic deformation, the movement of the domain walls is impeded due to the significant amount of defects introduced to the material. However, a lesser decrease in the $\operatorname{Int}\left(\mathrm{U}_{\mathrm{a}}\right)_{\text {norm }}$ values for specimens after accelerated creep than for specimens after tensile tests was observed due the applied temperature (773 K). 


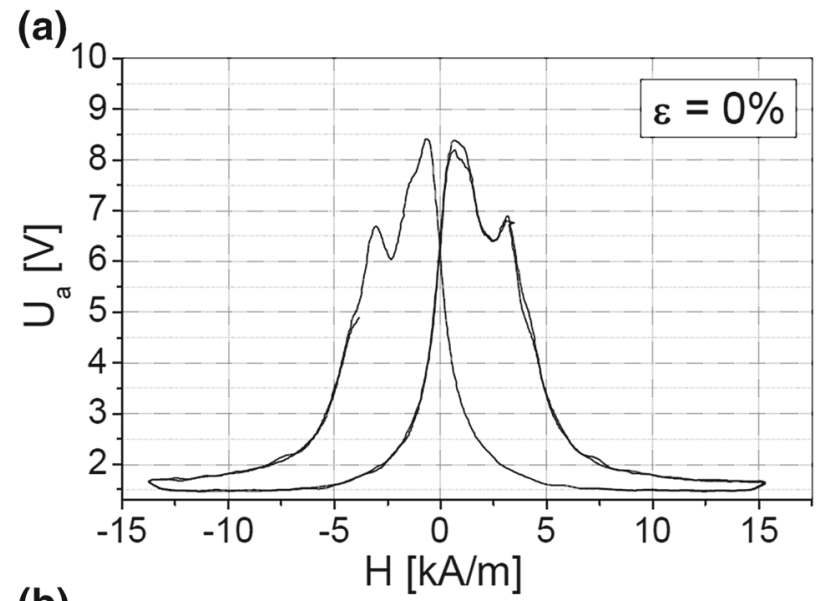

(b)

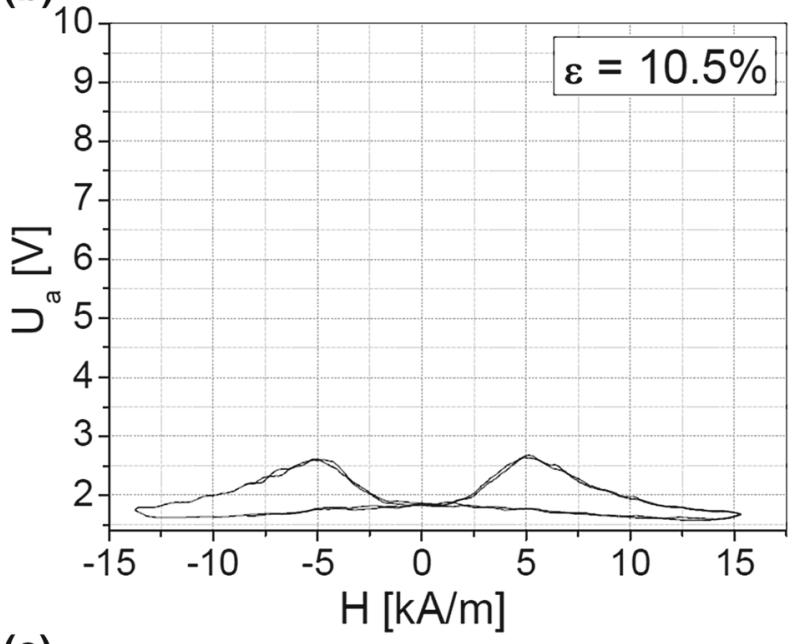

(c)

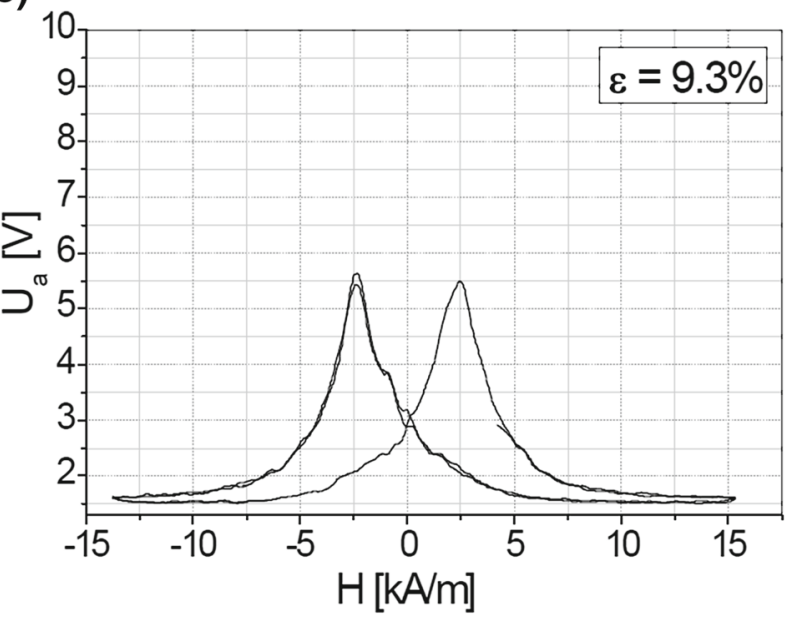

Fig. 4 The magnetoacoustic emission rms envelopes for specimens of the P91 steel: a non-deformed, $\mathbf{b}$ after plastic deformation up to $10.5 \%$, c after creep up to $9.3 \%$ [2]

The quasi-exponential relationships between coercivity and prior deformation level can be found. For plastic deformation, the coercivity $\mathrm{H}_{\mathrm{c}}$ norm was higher than that after creep occurred (Fig. 6). In the case of saturation induction

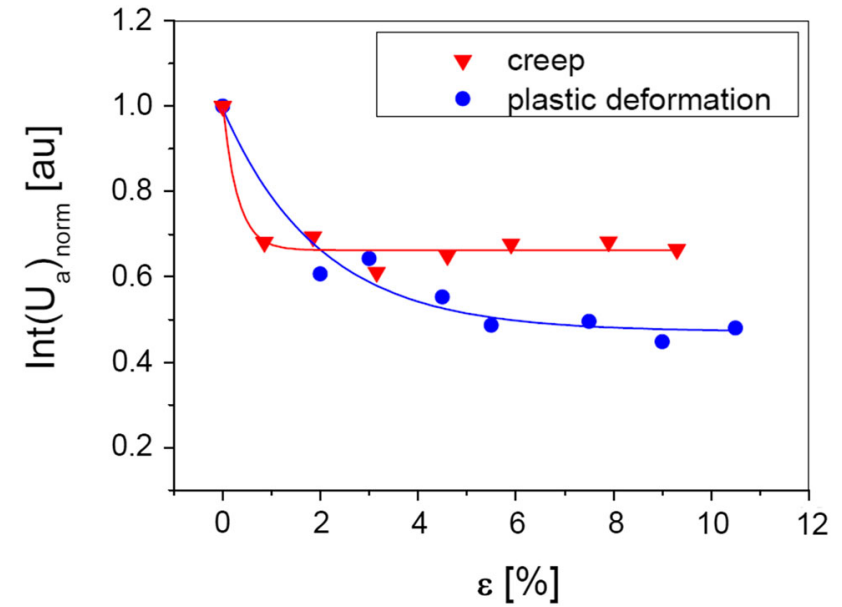

Fig. 5 Integral of half-period voltage signal of magnetoacoustic emission versus prior deformation of the P91 steel due to creep or plastic flow

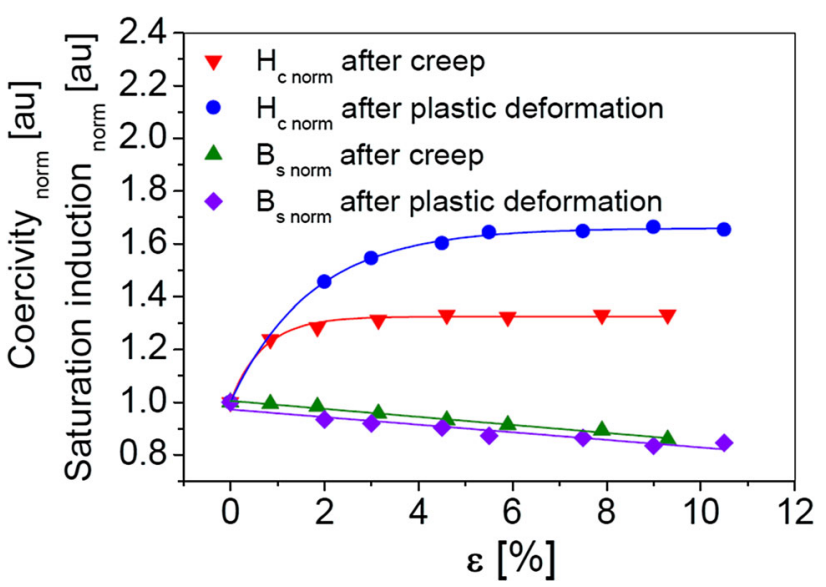

Fig. 6 Coercivity $\mathrm{H}_{\mathrm{c}}$ norm and saturation induction $\mathrm{B}_{\mathrm{s}}$ norm versus prior deformation of the P91 steel due to creep or plastic flow

$\mathrm{B}_{\mathrm{s} \text { norm }}$ considered as a function of the strain level produced by creep or plastic deformation different relationships were obtained. They can be described with reasonably good accuracy by the linear equations (Fig. 6).

The coercive force of the specimens after plastic deformation and after unloading is the sum of three terms [27]:

$H_{c}^{0}=H_{c}(\varepsilon=0)+\Delta H_{c}^{\sigma}(\rho)+\Delta H_{c}^{0}\left(\sigma_{\text {res }}\right)$

The first term $H_{c}(\varepsilon=0)$ represents the initial $\mathrm{H}_{c}$ value at the end of the elastic region. The second term reflects an increase of the dislocation density $\rho$ with increasing $\varepsilon$. The last term is determined by the residual stress, $\sigma_{\text {res }}$. According to Jiles [8] precipitates with different magnetic properties from those of the matrix material also act as pinning sites, which impede domain wall motion.

The last term is determined only by the level, sign and distribution of $\sigma_{\text {res }}$ [27]. Measurements of residual stress 
using the X-ray diffraction method indicate that tensile plastic deformation results in compressive residual stress [28]. When tensile stress is applied and exceeds the yield point, a rapid dislocation multiplication occurs [29]. The dislocations readily pile up and create dense dislocation tangles with a high degree of tensile deformation, leaving the bulk of the specimen in residual compression after unloading [29].

The appearance of residual compressive stresses in steel subjected to plastic tension after unloading is caused by the local anisotropy of the Young's modulus in each grain of the steel [27]. Bernshtein and Zaimovsk [30] also described this phenomenon for another material.

The unit cell of the material is characterized by crystallographic directions of higher and lower Young's modulus. We can call them 'mechanically rigid' and 'mechanically soft'. The first plastically deformed grains are those for which the crystallographic directions of lower Young's modulus are closest to the loading force. Upon unloading, the sizes of the "rigid" grains are reduced by a value of about $\varepsilon \sim \sigma_{\text {true }} / \mathrm{E}_{\text {rigid }}$ and the soft ones $\varepsilon \sim \sigma_{\text {true }} / \mathrm{E}_{\text {soft. }}$ The value is visibly higher for the "mechanically soft" direction than for the 'mechanically rigid' [27]. The adjacent grains with different orientations are joined by their boundaries and this leads to the appearance of residual compressive stresses in the elastically deformed ('rigid') grains as well. As a result, the grains that are more 'rigid' in the elastic sense become compressed upon unloading, which explains the increase in coercive force [27].

The crystallographic structure of the $\mathrm{P} 91$ steel is supposed to be close to body-centred cubic (BCC) [31]. Hence, the crystallographic 'mechanically soft' direction for the tested material is $<111\rangle$. Two families of slip systems, the $\{110\}$ or $\{112\}$ plane and $<111>$ slip direction, being the two easiest gliding systems for the tempered martensite ferritic steel [31, 32], were considered.

The values of parameters calculated on the basis of magnetic hysteresis loop were repeatable, because the tests were conducted for the entire volume of the material within the gauge length of specimen. Measurement of the magnetic hysteresis loop was sensitive to the contact quality between the specimen and core. Errors in calculation of the MAE integral were kept within 5-10\%.

Figure 7 presents the variation in the acoustic birefringence coefficient of the P91 steel versus the pre-strain induced by creep or plastic deformation. The process of pipe forming resulted in a measurable material texture that can be seen as a non-zero acoustic birefringence value for the material in the as-received state (Fig. 7). For both cases, an exponential decrease in the acoustic birefringence coefficient value was observed. However, for specimens after accelerated creep the changes of the coefficient are less. In the case of specimens deformed in low temperature, the acoustic birefringence decrease is mainly a result of material grain

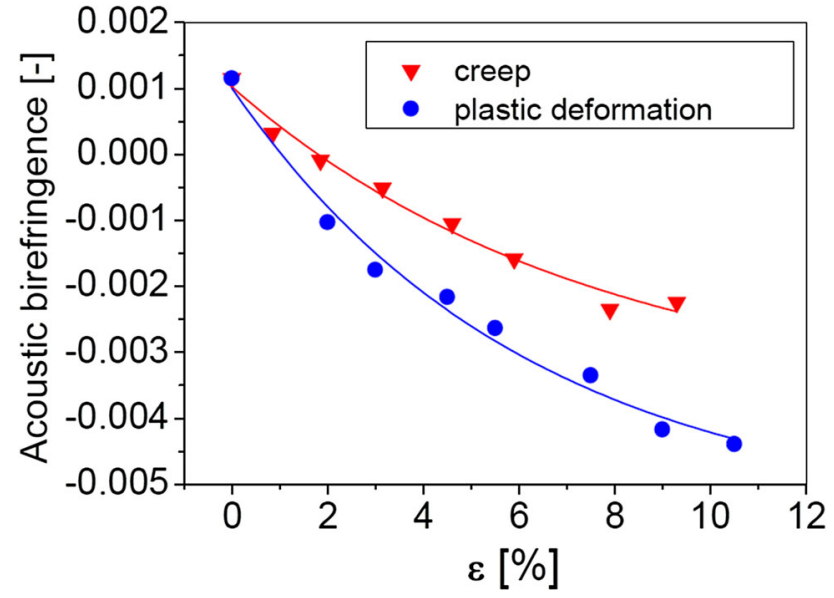

Fig. 7 Acoustic birefringence coefficient versus prior deformation of the P91 steel due to creep or plastic flow [33]

reorientation associated with unidirectional strain. This reorientation occurs in the direction of the easy slip directions of individual grains according to the direction of enforcing deformation [33]. Similar phenomena occur after accelerated creep. However, the effect of reorientation is smaller than that observed after plastic deformation at room temperature. Plastic deformation and accelerated creep produce new dislocations and new point defects during the mutual intersecting of the dislocations, but in the case of high temperature the new dislocations are pinned very fast by mobility in high temperature, and also quickly annihilate each other (due to the tempering process). Therefore, there is no such strengthening as that obtained during plastic deformation, the effects of reorientation are smaller and only small anisotropy in the material remains. Some errors in acoustic birefringence calculations are mainly attributed to the accuracy of the defectoscope used during the time of flight measurements of waves propagating in specimens ( $\pm 1 \mathrm{~ns}$ ). In our program the length of wave propagation was approximately $8 \mathrm{~mm}$ (double thickness of specimen), which gives an error for acoustic birefringence measurement equal to $\pm 0.08 \%$.

The studies based on parameters determined from the nondestructive tests with respect to the deformation indicate the strongest functional relationship between $\mathrm{B}_{s}$ and $\varepsilon$. This is due to physical phenomena that occur during the magnetisation of ferromagnetic material and can be described by the magnetic hysteresis loop. Saturation induction determines the value above which we do not have a further increase of material magnetization. In the material that has reached the saturation induction some physical processes may take place during the magnetization.

In the range of low intensity of the external magnetic field the reversible domain walls movement occurs, especially $180^{\circ}$ ones. An influence of external magnetic field on the ferromagnetic material causes a gradual reorientation of its 
domain structure. Magnetic domains with the dipole moment directions close to the direction of the magnetic field grow at the expense of the magnetic domains of dipole moment directions substantially different from the direction of the external field producing domain walls movements.

In the area of linear relationship $\mathrm{B}(\mathrm{H})$ of magnetic hysteresis loop a further increase of single domain at the expense of others takes place. This is an irreversible process and it occurs until the magnetic domains of the dipole directions, other than the direction of the external magnetic field, disappears completely.

For upper curvature of the magnetic hysteresis loop the ferromagnetic material enters a state close to saturation, i.e. the vectors of magnetization of domains rotate from the direction of easy magnetization axis to the direction of the external magnetic field. This is the third reversible process that is associated with saturation induction. Domains do not change their volume.

Barkhausen noise and coercive field are linked to each other [9]. Barkhausen noise maximum intensity occur for values of magnetic field close to the coercive field, but the magnetoacoustic emission maxima are observed for the "knee" regions of the hysteresis loops where the creation/annihilation of $90^{\circ}$ domain walls take place [34]. So, it can be concluded, that the strength of relationships between parameters coming from non-destructive and destructive tests may be associated with a range of magnetic field intensity, and therefore, with diversity of physical phenomena occurring during the magnetization cycle.

The acoustic birefringence is associated with rotation of the materials grains which rotate and tend to set directions of the easy sliding parallel to the main axis of deformation. Therefore, the change of acoustic birefringence value corresponds solely to a single physical phenomenon.

The static tensile tests were carried out in order to perform structuroscopic investigations [35-38]. The results of the mechanical tests conducted on specimens with prior deformation are presented in Fig. 8. The yield point and ultimate tensile stress variations demonstrate the softening effect in the P91 steel after creep, whereas after plastic deformation a hardening effect can be observed.

However, the main aim of the experiment was to find relationships between those mechanical and non-destructive parameters which would be sensitive to damage development. The results of the second part of the experimental programme devoted to this issue are shown in Figs. 9, 10, $11,12,13,14,15$ and 16.

Since the yield stress of the P91 steel was insensitive to the deformation level for the strain induced by creep, it will not be considered in further analysis. Figure 9 presents the exponential relationships in a certain range of changes between the yield stress and integral of the MAE rms envelopes (range 0-9\%). Also exponential relationship

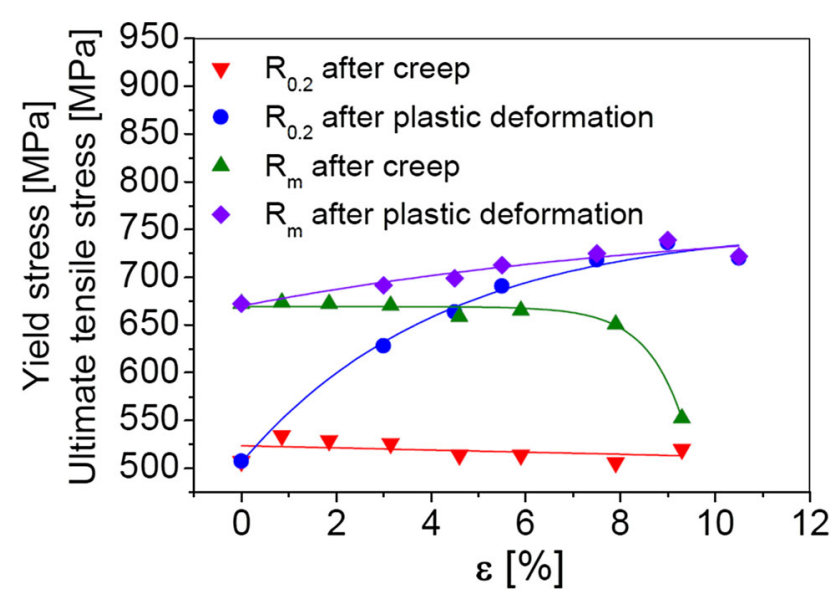

Fig. 8 Variation of yield stress $\mathrm{R}_{0.2}$ and ultimate tensile stress $\mathrm{R}_{m}$ of the P91 steel due to prior deformation [38]

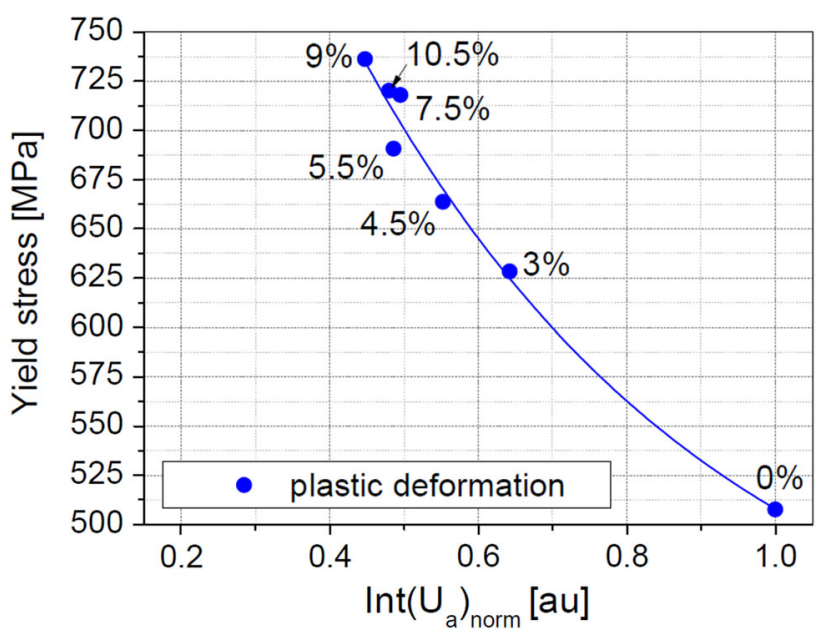

Fig. 9 Variation of yield stress of the P91 steel versus integral of halfperiod voltage signal $\operatorname{Int}\left(\mathrm{U}_{\mathrm{a}}\right)_{\text {norm }}$ of magnetoacoustic emission

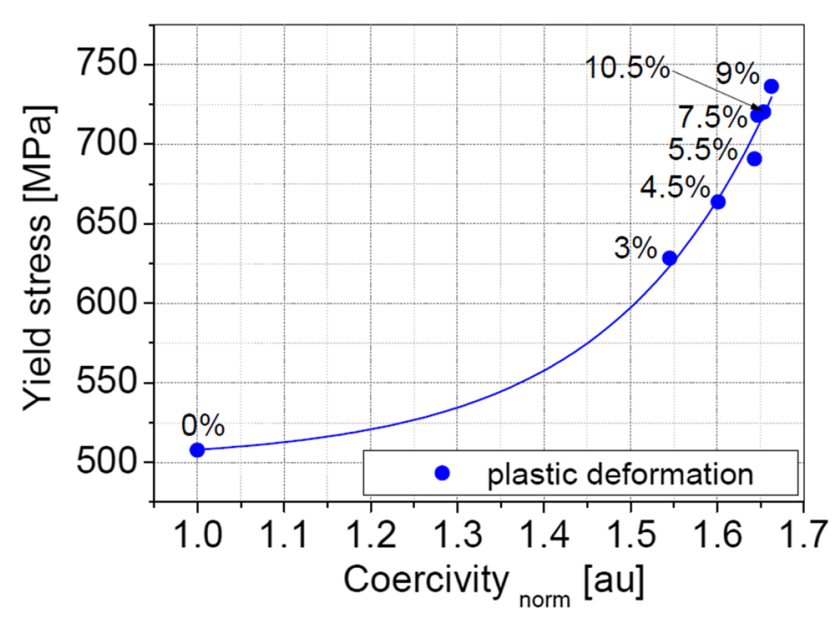

Fig. 10 Variation of yield stress of the P91 steel versus coercivity $\mathrm{H}_{\mathrm{c} \text { norm }}$ 


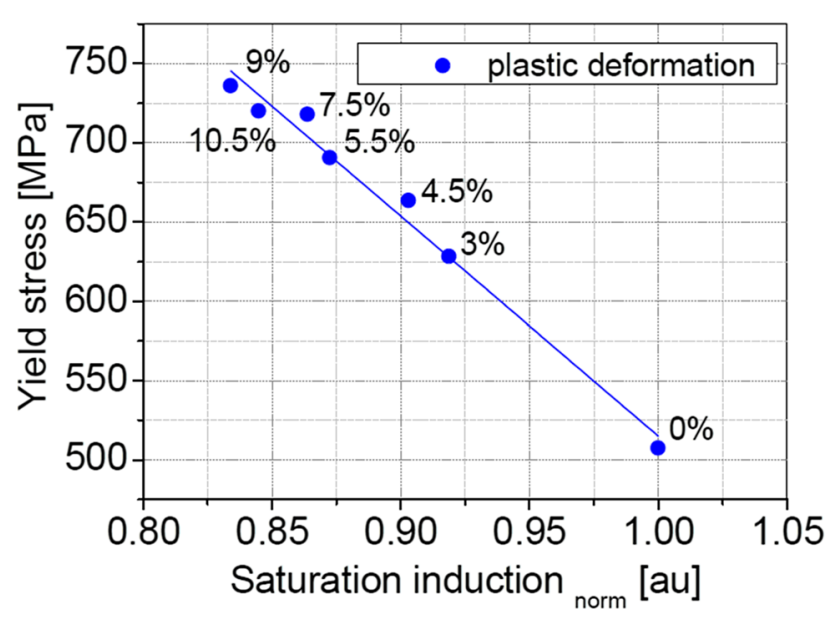

Fig. 11 Variation of yield stress of the P91 steel versus saturation induction $\mathrm{B}_{\mathrm{s} \text { norm }}$

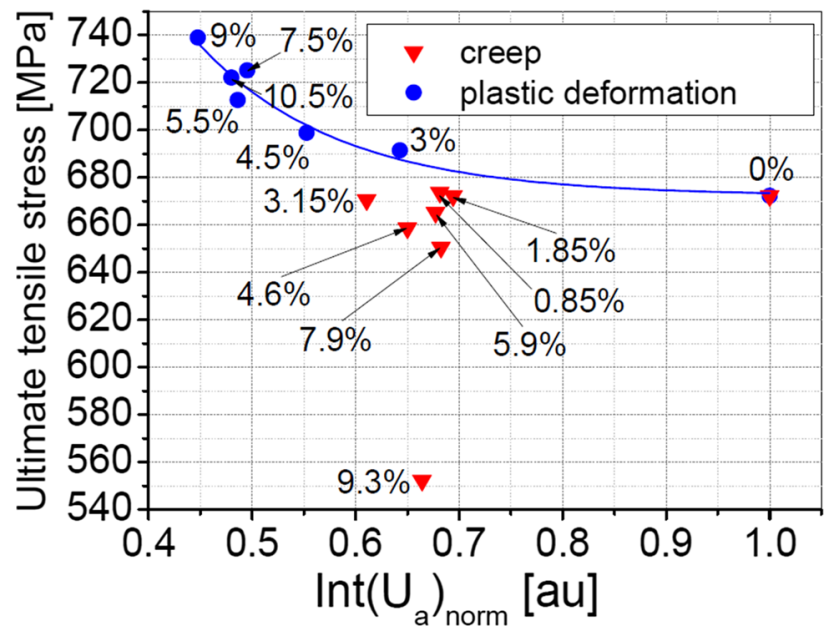

Fig. 12 Variation of ultimate tensile stress of the P91 steel versus integral of magnetoacoustic emission $\operatorname{Int}(\mathrm{Ua})_{\text {norm }}$

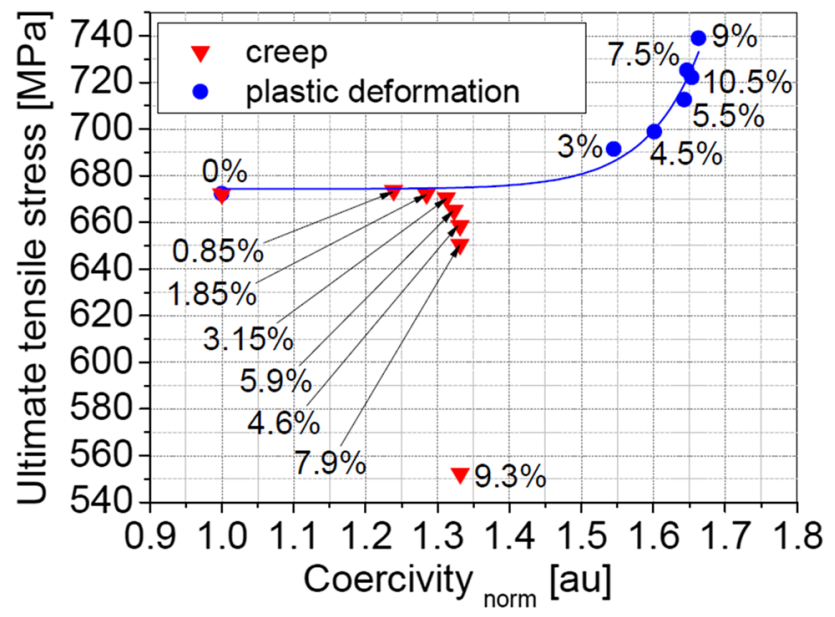

Fig. 13 Variation of ultimate tensile stress of the P91 steel versus coercivity $\mathrm{H}_{\mathrm{c} \text { norm }}$

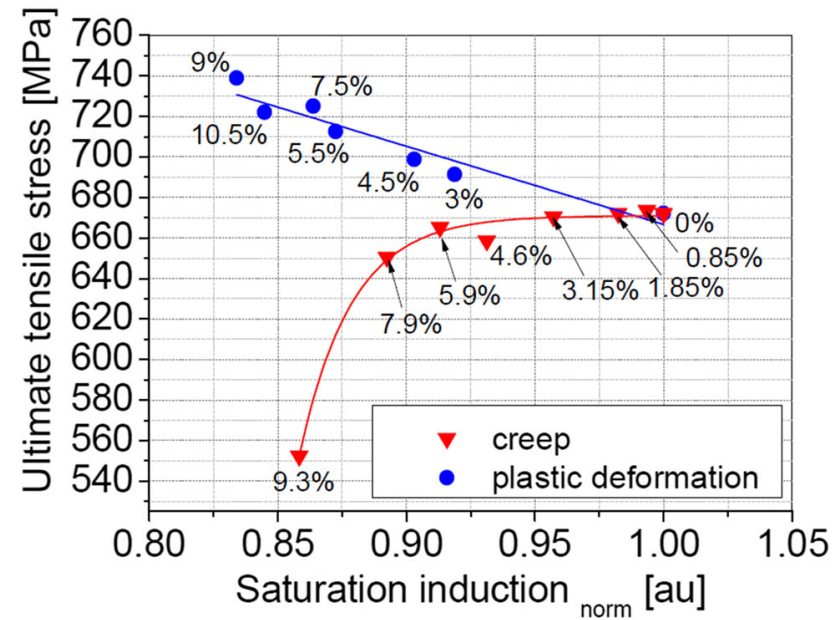

Fig. 14 Variation of ultimate tensile stress of the P91 steel versus saturation induction $\mathrm{B}_{\mathrm{s} \text { norm }}$

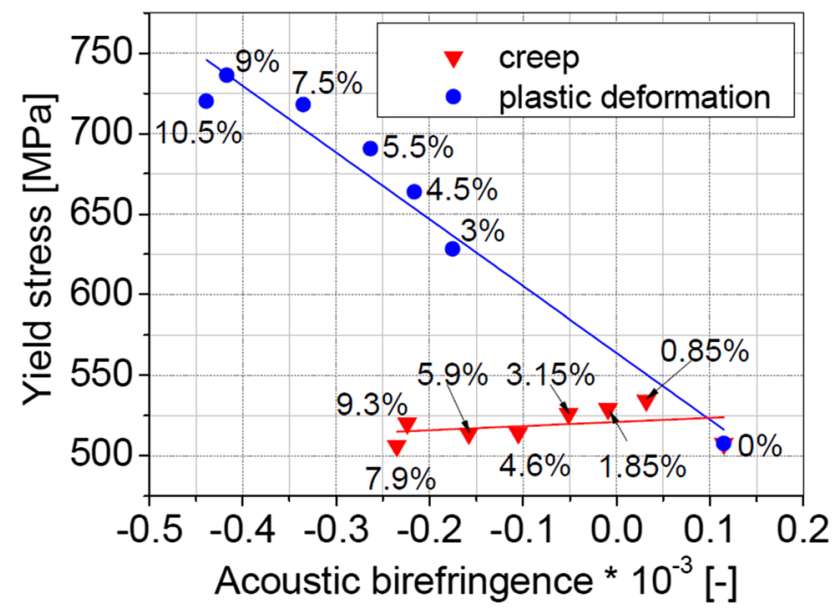

Fig. 15 Variation of yield stress of the P91 steel versus acoustic birefringence

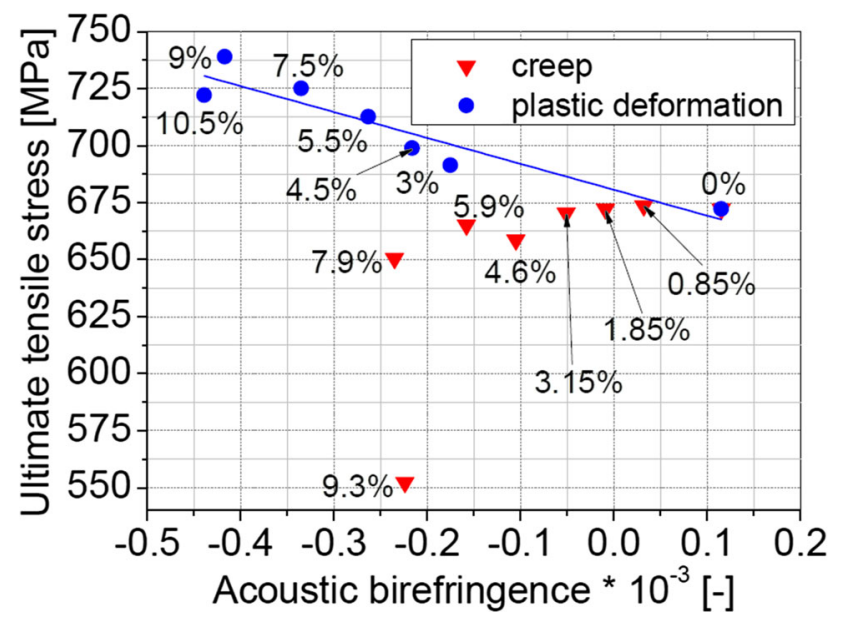

Fig. 16 Variation of ultimate tensile stress of the P91 steel versus acoustic birefringence 
between the coercivity and yield stress of the steel after plastic deformation were found (range 0-9\%) (Fig. 10). It can be seen that the yield stress decreases with the integral of the magnetoacoustic emission whereas it increases in relation to coercivity.

Depending on the parameters considered, their mutual relationship exhibits different behaviour. Contrary to just mentioned parameters, in the case of the yield stress and saturation one can notice a linear relationship in the strain range taken into account (0-9\%), Fig. 11.

Figures 12, 13, and 14 show the relationships between the ultimate tensile stress and selected magnetic parameters. Similar to the results obtained for the yield stress, in the case of plastic deformation the exponential relationships between the ultimate tensile stress and magnetoacoustic emission integral can be observed in the strain levels considered (0-9\%) here, Fig. 12. It has to be noted however, that for the steel after creep the mutual relationship between these parameters cannot be expressed as a function, since the points representing increasing level of deformation are not located in the orderly manner. The same types of relationships were found between the ultimate tensile stress and the coercivity, Fig. 13. Contrary to these results, variations of the saturation induction $\mathrm{B}_{\mathrm{s} \text { norm }}$ allow an estimation of the ultimate tensile stress of the P91 steel either after creep (in the whole range) or plastic deformation (range 0-9\%), Fig. 14. The relation $\mathrm{R}_{\mathrm{m}}=\mathrm{f}\left(\mathrm{B}_{\mathrm{s} \text { norm }}\right)$ for the material after plastic deformation can be described by the linear function, whereas that after creep, by exponential one.

Also selected ultrasonic damage sensitive parameters can be correlated with the mechanical ones. In our case we have found the acoustic birefringence coefficient as that which gives very promising results. Figures 15 and 16 summarise some achievements in this area. Figure 15 illustrates mutual relationship between the acoustic birefringence coefficient and yield stress, whereas in Fig. 16 the same parameter is presented as a function of ultimate tensile stress. The numbers in figures denote the level of prior deformation. The yield stress of

the P91 steel after deformation induced by creep almost does not change with the acoustic birefringence coefficient. In the case of plastic deformation the mechanical parameters decrease linearly with an increase of acoustic birefringence coefficient.

\section{Conclusions}

The results obtained for the P91 steel suggest that it is possible to find the functional relationships between damage sensitive parameters coming from mechanical tests and those determined from non-destructive investigations. It has been shown that the yield stress of the P91 steel after prior plastic deformation may be estimated by means of all the suggested parameters. The saturation induction may be used for determination of the ultimate tensile stress of the steel subjected to prior creep or plastic deformation.

The parameters obtained using magnetic and ultrasonic techniques permit the recognition of the type of deformation process. An identification of the loading history is possible for medium and higher values of strain $\varepsilon$ from $\sim 4.6 \%$ to 9.3\% using the acoustic birefringence coefficient, or applying parameters that could be determined from MAE rms envelopes (integral) as well as from magnetic hysteresis loops (coercive field, saturation induction).

Saturation induction was found to be the only parameter obtained from the magnetic method that enabled identification of prior deformation stage, yield stress as well as ultimate tensile stress. Also the kind of deformation process could be determined for the $\mathrm{P} 91$ steel tested under conditions defined in this research (accelerated creep: $\sigma=290 \mathrm{MPa}, \mathrm{T}=773 \mathrm{~K}$; plastic deformation: $\mathrm{T}=298 \mathrm{~K}$ ).

The correlation discovered between the selected parameters derived from non-destructive and destructive tests may serve as the starting point that enables evaluation of the mechanical properties of materials using only nondestructive investigations.

Acknowledgements The research was undertaken within the financial support of the Motor Transport Institute (No. 6019/CBM) and the National Centre of Science, Poland, Grant No. 2014/15/B/ST8/04368.

Open Access This article is distributed under the terms of the Creative Commons Attribution 4.0 International License (http://creativecomm ons.org/licenses/by/4.0/), which permits unrestricted use, distribution, and reproduction in any medium, provided you give appropriate credit to the original author(s) and the source, provide a link to the Creative Commons license, and indicate if changes were made.

\section{References}

1. Govindaraju, W.R., Kaminski, D.A., Devine, M.K., Biner, S.B., Jiles, D.C.: Nondestructive evaluation of creep damage in powerplant steam generators and piping by magnetic measurements. NDT\&E Int. 30, 11-17 (1997)

2. Augustyniak, B., Chmielewski, M., Piotrowski, L., Kowalewski, Z.L.: Comparison of properties of magnetoacoustic emission and mechanical Barkhausen effects for P91 steel after plastic flow and creep. IEEE Trans. Magn. 44, 3273-3276 (2008)

3. Piotrowski, L., Augustyniak, B., Chmielewski, M.: On the possibility of the application of magnetoacoustic emission intensity measurements for the diagnosis of thick-walled objects in the industrial environment. Meas. Sci. Technol. 21, 1-8 (2010)

4. Mitra, A., Mohopatra, J.N., Swaminathan, J., Ghosh, M., Panda, A.K., Ghosh, R.N.: Magnetic evaluation of creep in modified $9 \mathrm{Cr}-$ 1Mo steel. Scr. Mater. 57, 813-816 (2007)

5. Mohopatra, J.N., Bandyopadhyay, N.R., Gunjan, M.K., Mitra, A.: Study of high-temperature ageing and creep on bainitic $5 \mathrm{Cr}-0.5 \mathrm{Mo}$ steel by magnetic NDE techniques. J. Magn. Magn. Mater. 322, 589-595 (2010) 
6. Sposito, G., Ward, C., Cawley, P., Nagy, P.B., Scruby, C.: A review of non-destructive techniques for the detection of creep damage in power plant steels. NDT\&E Int. 43, 555-567 (2010)

7. Buttle, D.J., Briggs, A.D., Jakubovics, J.P., Little, E.A., Scruby, C.B.: Magnetoacoustic and Barkhausen emission in ferromagnetic materials. Philos. Trans. R. Soc. Lond. A320, 363-378 (1986)

8. Jiles, D.: Introduction to Magnetism and Magnetic Materials, 2nd edn. Taylor and Francis Group, New York (1998)

9. Blaow, A., Evans, J.T., Shaw, B.A.: The effect of microstructure and applied stress on magnetic Barkhausen emission in induction hardened steel. J. Mater. Sci. 42, 4364-4371 (2007)

10. O’Sullivan, D., Cotterell, M., Cassidy, S., Tanner, D.A., Mészáros, I.: Magneto-acoustic emission for the characterisation of ferritic stainless steel microstructural state. J. Magn. Magn. Mater. 271, 381-389 (2004)

11. Kwan, M.M., Ono, K., Shibata, M.: Magnetomechanical acoustic emission of ferromagnetic materials at low magnetization levels (Type I Behaviour). J. Acoust. Emiss. 3, 144-156 (1984)

12. Augustyniak, B., Piotrowski, L., Chmielewski, M., Sablik, M.: Creep damage zone detection in exploited power plant tubes with magnetoacoustic emission. Przegląd Elektrotechniczny 83, 93-98 (2007)

13. Brithel, L.: Macroscopic measurements of creep damage in metals. Stand. J. Metall. 7, 199-203 (1978)

14. Ohtani, T., Ogi, H., Hirao, M.: Evolution of microstructure and acoustic damping during creep of a Cr-Mo-V ferritic steel. Acta Mater. 54, 2705-2713 (2006)

15. Kim, C.S., Park, I.K., Jhang, K.Y.: Nonlinear ultrasonic characterization of thermal degradation in ferritic $2.25 \mathrm{Cr}-1 \mathrm{Mo}$ steel. NDT\&E Int. 42, 204-209 (2009)

16. Szelążek, J., Mackiewicz, S., Kowalewski, Z.L.: New samples with artificial voids for ultrasonic investigation of material damage due to creep. NDT\&E Int. 42, 150-156 (2009)

17. Schneider, E.: Ultrasonic birefringence effect-its application for materials characterisations. Opt. Laser Eng. 22, 305-323 (1995)

18. Schramm, R.E., Szelążek, J., Clark Jr., A.V.: Ultrasonic measurement of residual stress in the rims of inductively heated railroad wheels. Mater. Eval. 54, 929-934 (1996)

19. Mackiewicz, S.: Opportunities for steel ultrasonic degradation assessment of energy as a result of long-term use [in Polish]. In: Proceedings of the 7th Symposium of Information and Training on Diagnosis and Repair of Long Operating Power EquipmentNew Diagnostic Problems on the Old Power Units. Ustroń, Poland (2005)

20. Panait, C., Bendick, W., Fuchsmann, A., Gourgues-Lorenzon, A.F., Besson, J.: Study of the microstructure of the Grade 91 steel after more than $100^{\prime} 000 \mathrm{~h}$ of creep exposure at $600^{\circ} \mathrm{C}$. In: Proceedings of the 2nd ECCC Creep Conference. Zurich, Switzerland (2009)

21. Šohaj, P., Jan, V., Dvořáček, O.: Evaluation of microstructural stability of creep-resistant steels weld joints on the basis of computational modeling (2010). http://konsys-t.tanger.cz/files/ proceedings/metal10/lists/papers/44.pdf

22. Augustyniak, B.: Magnetomechanical Effects and Their Application in Nondestructive Evaluation of Materials (in Polish). Monography, 38th edn. Gdansk University of Technology, Gdańsk, Gdańsk (2003)
23. Baldev, R., Jayakumar, T., Moorthy, V., Vaidyanathan, S.: Characterization of microstructures, deformation and fatigue damage in different steels using magnetic Barkhausen emission technique. Russ. J. Nondestruct. 37:789-798 (2001) translated from. Defektoskopiya 11, 39-50 (2001)

24. Zakharov, V.A., Ul'yanov, A.I., Gorkunov, E.S., Velichko, V.V.: Coercive-force hysteresis of carbon steels during elastic cyclic tensile deformation. Russ. J. Nondestruct. 49, 260-269 (2013)

25. Bailey, R.W.: The utilization of creep test data in engineering design. Proc. Inst. Mech. Eng. Proc. 131, 131 (1935)

26. Frost, H.J., Ashby, M.: Deformation-Mechanism Maps. The Plasticity and Creep of Metals and Ceramics. Pergamon Press, New York (1982)

27. Kuleev, V.G., Tsar'kova, T.P., Nichipuruk, A.P., Voronin, V.I., Berger, I.F.: On the origin of essential differences in the coercive force, remanence, and initial permeability of ferromagnetic steels in the loaded and unloaded states upon plastic tension. Phys. Met. Metallogr. 103, 131-141 (2007)

28. Rusnak, R.M., Cullity, B.D.: Correlation of magnetic permeability and X-ray diffraction line broadening in cold-worked iron. J. Appl. Phys. 40, 1581-1582 (1969)

29. Thompson, S.M.: The magnetic properties of plastically deformed steels. Dissertation, Durham University (1991)

30. Bernshtein, M.L., Zaimovsk, V.A.: Structure and Mechanical Properties of Metals. Metallurgiya, Moscow (1970). in Russian

31. Sauzay, M.: Modeling of the evolution of micro-grain misorientations during creep of tempered martensite ferritic steels. Mater. Sci. Eng. A 510-511, 74-80 (2009)

32. Fournier, B., Sauzay, M., Pineau, A.: Micromechanical model of the high temperature cyclic behavior of $9-12 \% \mathrm{Cr}$ martensitic steels. Int. J. Plast. 27, 1803-1816 (2011)

33. Mackiewicz, S., Kowalewski, Z.L., Szelążek, J., Deputat, J.: Mechanical and ultrasonic research of materials failure condition due to creep process. Mech. Rev. 7-8, 15-24 (2005). in Polish

34. Bida, G.V., Nichipuruk, A.P.: Multiparameter methods in magnetic structuroscopy and nondestructive testing of mechanical properties of steels. Russ. J. Nondestruct. Test. 43, 493-509 (2007)

35. Dobmann, G.: Non-Destructive Testing for Ageing Management of Nuclear Power Components, Chapter 17 of Nuclear Power Control, Reliability and Human Factors ed. by Pavel Tsvetkov. Publisher InTech, ISBN 978-953-307-599-0 (2011). http://cdn. intechopen.com/pdfs-wm/21065.pdf

36. Skrbek, B., Dočekal, J., Tomáš, I.: Quantitative NDT structuroscopy of cast iron castings for vehicles (cars and locomotives). NDT for Safety (2007). http://www.ndt.net/article/ ENDTdays2007/ndtinprogress/20.pdf

37. Dočekal, J., Skrbek, B., Tomáš, I.: Mapping of mechanical properties of cast iron melts using non-destructive structuroscopy. Arch. Foundry Eng. 8, 155-161 (2008)

38. Makowska, K.M., Kowalewski, Z.L., Augustyniak, B., Piotrowski, L.: Determination of mechanical properties of P91 steel by means of magnetic Barkhausen emission. J. Theor. Appl. Mech. 52, 181188 (2014) 